\title{
The great debate: does it matter how you lower blood pressure?
}

\author{
B Rayner, ${ }^{1}$ M Heradien ${ }^{2,3}$ \\ ${ }^{1}$ Division of Nephrology and Hypertension, Groote Schuur Hospital and University of Cape Town, South Africa \\ ${ }^{2}$ Department of Medicine, Faculty of Medicine and Health Sciences, Stellenbosch University, South Africa \\ ${ }^{3}$ Netcare Kuils River Hospital, South Africa \\ Corresponding author, email: brian.rayner@uct.ac.za
}

The great debate between eminent experts Prof. Brian Rayner, Nephrologist (UCT), and Dr Marshall Heradien, Cardiologist (Stellenbosch University), on "Does it matter how you lower blood pressure (BP)," was moderated by Prof. Nqoba Tsabedze, Cardiologist (Wits), and hosted online by Servier. Prof. Rayner took the position that it does not matter how you lower your blood pressure, while Dr Heradien took the position that it does. This transcript highlights their salient points and provides compelling evidence to support their respective stances.

\section{Prof. Brian Rayner: It does not matter how you lower your blood pressure}

\section{Historical perspective}

In the 1930s it was thought that "the greatest danger to a man with high blood pressure lies in its discovery, because some fool is certain to lower it." Professor Dudley White in 1937 said: "Hypertension may be an important compensatory mechanism that should not be tampered with, even if we're certain we could control it." This was the prevailing viewpoint at that time. In fact it was so prevailing that the President of the United States, Franklin D. Roosevelt, who had hypertension, was very carefully monitored until his blood pressure reached $300 \mathrm{mmHg}$ systolic, when he unexpectedly died of a haemorrhagic stroke!

Life insurance companies showed this very strong relationship between blood pressure and the risk of death, which was four to five-fold higher if your blood pressure was between 153-177 systolic or 96-116 mmHg diastolic. ${ }^{1}$ We know now, with greater data, that our true risk starts at 115/75 and doubles for every $20 / 10$ of $\mathrm{mmHg}$. So at $175 / 105 \mathrm{mmHg}$ we have an eight-fold increased risk. $^{2}$

Because of the scepticism that lowering blood pressure was beneficial, placebo-controlled studies were conducted in the 1970s, including on a diuretic-based regimen of hydralazine - a very short-acting and old drug - which clearly showed the incidence of all morbid events was highly significantly reduced over five years. ${ }^{3}$ Therefore, it is not ethical to ever do a placebocontrolled study in hypertension. These benefits were further delineated: for every $12 \mathrm{mmHg}$ lowering in systolic blood pressure, stroke was reduced by $40 \%$, myocardial infarction by $25 \%$, and heart failure by $50 \%$; and at Stage 1 hypertension, $12 \mathrm{mmHg}$ lowering over 10 years, you only needed to treat 11 to prevent one death. ${ }^{4}$ These analyses did not specify which drug you are using.

Currently, we have many meta-analyses, including one done by Bundy et al. ${ }^{5}$ which revealed that if you lower from 125-129 $\mathrm{mmHg}$ vs $102-124 \mathrm{mmHg}$, you lower cardiovascular events.
Obviously the higher the initial blood pressure and the lower you go, you can lower events by as much as $45 \%$. It is clear that lowering blood pressure is really the most critical issue in preventing cardiovascular events. ${ }^{6}$ The recent 2020 International Society of Hypertension (ISH) Global Hypertension Practice Guidelines state that it is essential to lower blood pressure by at least $20 \mathrm{mmHg}$ and ideally to $140 / 90 \mathrm{mmHg}$, although the optimal blood pressure is less than $130 / 80 \mathrm{mmHg}{ }^{7}$ Many poorer countries are unable to meet the latter target.

We have a vast range of drugs now for the treatment of hypertension, developed from the 1900s, including spironolactone (1957), methyldopa (1960), beta blockers (1973), peripheral alpha-1 blockers (1975), ACE-inhibitors (1977), calcium channel blockers (1977) and angiotensin II receptor blockers (1993). ${ }^{1}$ More recently, renal denervation and, in my opinion, sodium glucose transport inhibitors in diabetics are very useful antihypertensive agents, although they are not registered for this.

\section{Prevalence, missed treatment opportunities and physician inertia}

We have seen this amazing rise in hypertension prevalence, particularly in sub-Saharan Africa, sometimes over $45 \% .^{8}$ In South Africa the prevalence has almost doubled, particularly in younger people, similar for men and women. Death attributable to hypertensive disease in one year, in 2000 is far in excess of anything that COVID-19 is going to do in South Africa., ${ }^{9,10}$ In subSaharan Africa, half a million deaths in 2010, and 10 million years of lives lost were due to uncontrolled hypertension. ${ }^{11}$

In my view, hypertension is the Cinderella of risk factors. It was the late Professor Bongani Mayosi who said, "To combat heart disease, diabetes and stroke in Africa, hypertension is your number one best buy." If we control blood pressure, survival and renal events are better, compared with uncontrolled or apparent treatment resistance. ${ }^{12}$ If you reverse this, and you continue to be uncontrolled, you have accumulated mortality. If you have control, you have a highly significant reduction in 
mortality. ${ }^{13}$ Why is it then, that even in high income countries, only $19 \%$ of hypertensives are controlled, in upper-middle income countries $15.6 \%$, in lower-middle income about $10 \%$, and in low-income countries $12.7 \%$ ? $^{14}$ Sub-Saharan Africa has about an $8-9 \%$ control rate. So we're missing screening, treatment, and so on. But even if we treat, we only achieve control in less than $15 \%$ of hypertensive patients. ${ }^{15}$ We now know that hypertension - not to forget about diabetes - is a major risk for patients dying of COVID-19. I'm sure that if patients had controlled blood pressure, they'd have a better outlook. It is critical to lower blood pressure to prevent morbidity and mortality.

So what are we missing here? Are we giving the wrong signs to people? This issue of inadequate management or physician inertia was described as early as 1998. If your diastolic blood pressure is greater than $90 \mathrm{mmHg}$ and you had a change of medication on a previous visit, you have a 35\% chance of having your antihypertensive treatment increased, but if there was no change in medication and your systolic blood pressure is greater than $155 \mathrm{mmHg}$, only a $25 \%$ chance of escalating therapy, whereas if you are on an unscheduled visit with a systolic $<155 \mathrm{mmHg}$, there is a $0 \%$ chance of receiving additional treatment. ${ }^{16}$ Looking at England in 2011, not much has changed. ${ }^{17}$ Most hypertensive patients should be on two drugs, but only $45 \%$ of patients are on one drug and $36 \%$ on two drugs. So there's further evidence of physician inertia. Long-term follow-up of patients has shown that the number of controlled vs uncontrolled patients followed up, over five years, did not change: around $20 \%$ of patients remained controlled, while $39 \%$ remained uncontrolled. So it is not a good story when looking at physicians' attitude to treating hypertension. ${ }^{18}$

The Kaiser Permanente is a major managed health care in the United States, and they took hypertension seriously, because they felt this was a cost effective way of reducing medical costs. They have almost doubled the number of patients on treatment. Their target doubled to $80 \%$ by introducing simple algorithms and prompts to make doctors actually escalate treatment. In 2011, 87\% reached target. ${ }^{19}$ The United States, with Public Health Authorities and Government and Private Sector and Academics, had a remarkable success story of treating hypertension; in particular in the stroke area, where the mortality was incredibly high, there was a dramatic decrease in strokes and heart disease by implementing strategies to control blood pressure.

Wendy Hoy, a nephrologist, went to far-flung areas of Australia for five years, where the Aboriginals reside, a very poor area with a very high incidence of death due to renal causes. She implemented simple strategies to control blood pressure and halved the mortality from renal disease. The tragedy was that within a year of leaving, it returned back to baseline. ${ }^{20,21}$ So really, there are simple strategies that are effective in controlling blood pressure even in deprived environments. ${ }^{20}$

\section{Strategies to control blood pressure}

Given this rise in hypertension prevalence, we need to have very simple strategies to control blood pressure because we are going to need to involve nurse practitioners as well as doctors. ${ }^{8}$ In South Africa, in the Private Sector, there are nearly nine million medical scheme beneficiaries, but 45 million dependent on public funding. Prevalence of hypertension is about $40 \%$. Only a hundred and twenty-one per thousand received treatment for hypertension in 2014, accounting for one million hypertensives. I've estimated the number of hypertensives in the Public Sector at about five million.

Considering drug costs, if medication costs R100 or R250 per month, that translates to R1 200 or R3 000 per annum. That makes a difference of R1.8 billion in costs for treatment. In the Public Sector, costs are lower in South Africa, and just R300R600; that's R1.5 billion. Governments are really strained in the current COVID-19 epidemic. The cost of medication is clearly an important factor, and also does not include treatments of other cardiovascular risk factors.

We really need to have adherence to Guidelines. You need to monitor, you need to diagnose, you need to treat, you need to initiate, you need to intensify therapy. And those are the fundamental things we should be doing, when we are managing patients with hypertension. ${ }^{19}$

So in practice perhaps, for persons who are working in solo or in clinics, opportunistic screening - whenever somebody comes to the clinic - screen for blood pressure. Patient awareness pamphlets, notice boards in the waiting room; what are the dangers of hypertension, the silent, stealth killer; lifestyle information - drug companies have brought wonderful sugar and salt charts, informing people simply what is high in sugar and salt. Implement anti-hypertension treatment according to Guidelines, treat to target and avoid this incredible inertia. Also, the Funders need to come to the party. They need to feed back to doctors on medication adherence ratios and drastically reduce red-tape in accessing drugs. This filling in of chronic application forms for hypertension to me, is archaic.

An important point I need to make, is that there are no head-tohead randomised controlled trials of same drugs either in single pill combinations or free on blood pressure response; there are no outcomes studies of a single pill vs free combinations or long acting vs shorter acting drugs on outcome. For example ASCOT was not a single pill combination study.

So the debate is really, individualised treatment vs Public Health, or Medical Aid policies to reduce drug costs and provide treatment for greater numbers. Someone really has to pay, so it is either the tax payer or the Medical Aid member. And does individualised treatment result in better outcomes and offset the extra costs of medication increase for this?

And there it is, over to you Dr Heradien for your response! Thank you very much for your attention. 


\section{Introducing REAPTAN \\ Perindopril Arginine - Amlodipine \\ The clone of COVERAM"露 \\ Perindopril Arginine - Amlodipine}

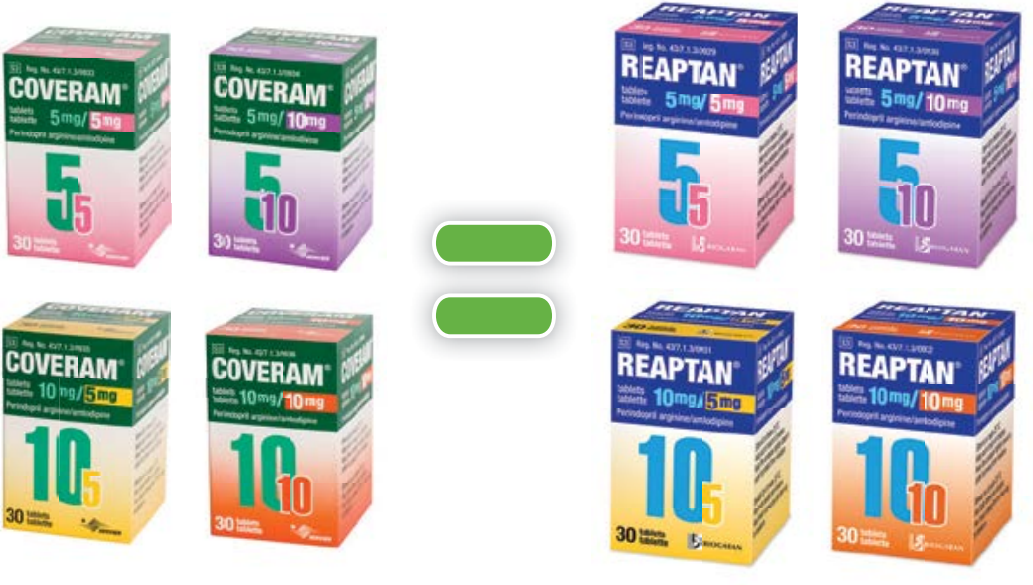

EFFECTIVE BP lowering

24 HR BP control

$\checkmark$ PROVEN CV* protection

WELL reimbursed

Fully reimbursed on all Discovery plans (except Keycare), all BestMed plans and all GEMs plans.

${ }^{*} \mathrm{CV}$ : Cardiovascular

Reference Safety Information - October 2019. What is Reaptan indicated for: Reaptan is indicated for the treatment of hypertension in patients already stabilised with perindopril and amlodipine at equivalen dosages. Treatment of hypertension in patients uncontrolled on either perindopril or amlodipine monotherapy. Do not use Reaptan in case of:* $*$ Hypersensitivity to the active substances, or to any other ACE-

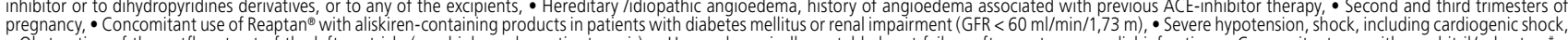

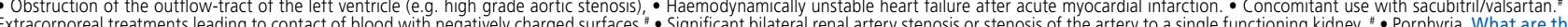
important identified risks and the main undesirable effects that may occur with Reaptan ${ }^{\circ}$ ? $*$ Hypersensitivity/Angioedema: * Angioedema of the face, extremities, lips, mucous membranes, tongue, glottis and/or larynx has been reported rarely in patients treated with ACE inhibitors, including perindopril. 0 . In such cases: discontinue Reaptan, initiate and continue appropriate monitoring until complete resolution of symptoms has occurred. In those instances where swelling was confined to the face and lips the condition generally resolved without treatment, although antihistamines have been useful in relieving symptoms.
Angioedema associated with laryngeal oedema may be fatal • Where there is involvement of the tongue, glottis or larynx, likely to cause airway obstruction, emergency therapy should be administered promptly. This Angioedema associated with laryngeal oedema may be fatal. - Where there is involvement of the tongue, glottis or larynx, likely to cause airway obstruction, emergency therapy should be administered promptly. This
may include the administration of adrenaline and /or the maintenance of a patent airway. $\bullet$ Patients with a history of ancioedema unrelated to ACE-inhibitor therapy may be at increased risk of angioedema while may include the administration of adrenaline and/or the maintenance of a patent airway. • Patients with a history of angioedema unrelated to ACE-inhibitor therapy may be at increased risk of angioedema while
receiving an ACE-inhibitor. • Intestinal angioedema has rarely been reported. Patients presented with abdominal pain (with or without nausea and vomiting): in some cases there was not prior facial engioedema and C-1 esterase levels were normal. 0 Due to increased risk of angioedema, sacubitril /valsartan must not be initiated until 36 hours after taking the last dose of perindopril therapy. Perindopril therapy must not be started - Concomitant use of other NEP inhibitors (e.g. racecadotril) and ACE-inhibitos may also increase the risk of angioedema. " Concomitant use of mTOR inhibitors may be at increased risk for angioedema. • Frequency: uncommon ( $21 / 1000$ to < 1/100). Neutropenia/Agranulocytosis/Thrombocytopenia: • Perindopril should be used with extreme caution in patients with

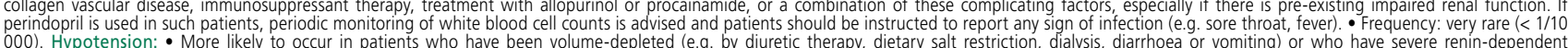

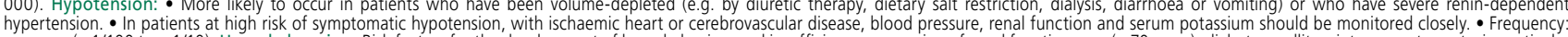
comminan 2 iln

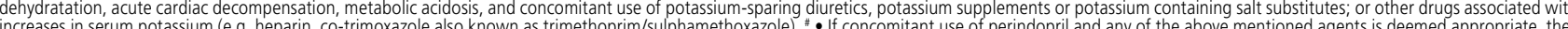
should be used with caution and with frequent monitoring of serum potassium. Frequency: uncommon (not known $(z 1 / 1000$ to $<1 / 10$ ). The other common undesirable effects of Reaptan" are somnolence,

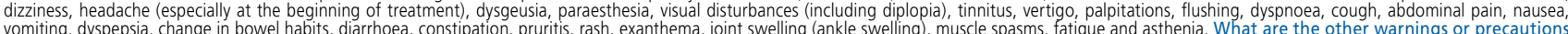
associated with the use of Reaptan`?* • Anaphylactoid reaction during - low-density lipoprotein (LDL) apheresis with dextran sulphate: rarely, patients have experienced life threatening anaphylactoid reactions, temporarily withnold treatment prior to exams. - desensitisation treatment (e.g. Hymenoptera venom): Temporarily withhold treatment prior to exams. These reactions reappeared upon inadvertent rechallenge. Renovascular hypertension: increased risk of hypotension and renal insufficiency when patient with bilateral renal artery stenosis or stenosis of the artery to a single functioning kidney are treated with ACE-inhibititors

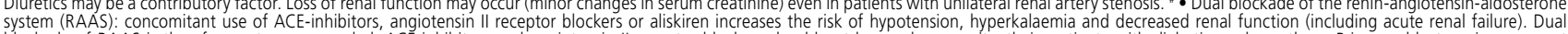
blockade of RAAS is therefore not recommended, ACE-inhibitors and angotensin I receptor blockers should not be used concomitantly in patients with diabetic nephropathy - Primary aldosteronism. Is D no recommended in patients with primary hyperaldosteronism (not responding medication acting through inhibition of the renin-angiotensin system). $\boldsymbol{*} \bullet$ Pregnancy: ACE-inhibitors should not be initiated during pregnancy. When pregnancy is diagnosed, stop treatment with ACE-inhibitors immediately and, if appropriate, start alternative therapyy • Mitral valve stenosis/obstruction in the outtllow of the left ventricle (e.g. aortic stenosis, hypertrophic cardiomyopathy), cardiac failure: use with caution. . In patients with renal artery stenosis, blood urea and creatinine may increase; with renovascular hypertension, risk of severe hypotension and renal insufficiency. Renal failure: amlodipine is not dialysable.
failure: rarelely ACE-inhibitic

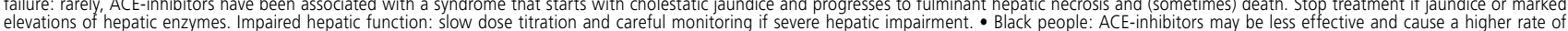

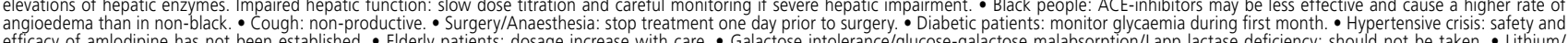
Potassium-sparing medicines/Potassium supplements/Dantrolene: not recommended. "Pending

References: Bahl V, et al. J Hypertens; 2010:e98. STRONG. Bahl VK, et al. Am J Cardiovasc Drugs 2009;9:135-142. PEARL-ABPM Nagy VL. Clin Drug Inves 2013; DOI 10.1007/540261-013-0086-9. SYMBIO Hatala R, et al. Clin Drug Inves 2012;32(9): 603-612. CREOLE Poulter N, et al. N Eng J Med 2019; DOl: 10.1056/NEJMoa1901113. ASCOT-BPLA Lancet 2005;366:895-906. ASCOT Legacy Published online Aug 26, 2018 http:///X.doi. org/10.1016/ S0140-6736(18)31776-8. Discovery Chronic Illness Benefit List January 2020. www. discovery.co.za. Medikredit Scheme Protocols January 2020. www.medikredit.co.za. Medscheme Comprehensive PMB Formulary and MPL
January 2020. www.medscheme.co.za. REAPTAN package insert approved by the Medicines Regulatory Authority, June 2019. COVERAM package insert approved by the Medicines Regulatory Authority, Feb 2018. Mediscor, accessed January 2020. www.mediscor.net.

3 Coveram ${ }^{\oplus} \mathrm{mg} / 5 \mathrm{mg}$ tablets: Perindopril arginine $5 \mathrm{mg}+$ Amlodipine $5 \mathrm{mg}$ (as besilate) Reg. №. 43/7.1.3/0933

Coveram $5 \mathrm{mg} / 10 \mathrm{mg}$ tablets: Perindopril arginine $5 \mathrm{mg}+$ Amlodipine $10 \mathrm{mg}$ (as besilate) Reg. No. 43/7.1.3/0934

Coveram $10 \mathrm{mg} / 5 \mathrm{mg}$ tablets: Perindopril arginine $10 \mathrm{mg}$ + Amlodipine $5 \mathrm{mg}$ (as besilate) Reg. No. 43/7.1.3/0935

$\mathrm{S} 3$ Coveram $10 \mathrm{mg} / 10 \mathrm{mg}$ tablets: Perindopril arginine $10 \mathrm{mg}$ + Amlodipine $10 \mathrm{mg}$ (as besilate) Reg. No. 43/7.1.3/0936.
For full prescribing information refer to latest Professional Information approved by the Regulatory Authority, 21 February 2018

NAME AND BUSINESS ADDRESS OF THE HOLDER OF THE CERTIFICATE: SERVIER LABORATORIES SOUTH AFRICA (Pty) Ltd. Reg. No. 72/14307/07. Building Number 4 Country Club Estate, 21 Woodlands Drive, Woodmead 2191. PO Box 930 , Rivonia 2128, Republic of South Africa. Building Number 4, Country Club Estate, 21 Woodl
Tel: +27 (0)861 700 900. Fax: +27 (0)11 5253401.

53 Reaptan $5 \mathrm{mg} / 5 \mathrm{mg}$ tablets: Perindopril arginine $5 \mathrm{mg}+$ Amlodipine $5 \mathrm{mg}$ (as besilate) Reg. No. 43/7.1.3/0929.

Reaptan $5 \mathrm{mg} / 10 \mathrm{mg}$ tablets: Perindopril arginine $5 \mathrm{mg}+$ Amlodipine $10 \mathrm{mg}$ (as besilate) Reg. No. 43/7.1.3/0930

Reaptan ${ }^{\oplus} 10 \mathrm{mg} / 5 \mathrm{mg}$ tablets: Perindopril arginine $10 \mathrm{mg}+$ Amlodipine $5 \mathrm{mg}$ (as besilate) Reg. No. 43/7.1.3/0931.

Reaptan $10 \mathrm{mg} / 10 \mathrm{mg}$ tablets: Perindopril arginine $10 \mathrm{mg}$ + Amlodipine $10 \mathrm{mg}$ (as besilate) Reg. No. 43/7.1.3/0932.

NAME AND BUSINESS ADDRESS OF THE HOLDER OF THE CERTIFICATE: BIOGARAN SOUTH AFRICA (Pty) Ltd. Reg. No. 2001/011749/07. Building Number 4 Country Club Estate, 21 Woodlands Drive, Woodmead, 2191. P.O. Box 2962, Rivonia, 2128, Republic of South Africa. Building Number 4, Country Club Estate, 21 Woodlands Drive, Woodmead,
TEL: +27(0)11 5253448 FAX: +27(0) 866465 144. 1920/1/Reap/Advert 
Dr Marshall Heradien: it matters how you reduce blood pressure

\section{Risk factors lead to endothelial dysfunction and sequelae}

I'm going to start off by sharing the "cardiovascular pathophysiological continuum" hypothesis, which states that if we do not control the five big risk factors that are all well known to us (hypertension, increased LDL, diabetes, smoking), they lead to oxidative stress and endothelial dysfunction. It is also important to remember that the endothelium is a lining of live cells that line the inside of the blood vessel and they actually secrete the vasoactive substance, nitric oxide. ${ }^{22}$ Nitric oxide is important because it dilates the vessel, but it also keeps the endothelium healthy, it prevents blood platelets from clotting or attaching to the endothelium, and it has other beneficial effects as well. If you don't control those risk factors, you will end up on the wheel of catastrophe, leading to tissue injury, pathological remodelling, target organ damage, end-organ failure and death. Therefore, it is important that you hit hard and fast when seeing the patient for the first time. ${ }^{22}$

A meta-analysis by Thomopoulos et al. showed reduced cardiovascular outcomes if you lower the blood pressure. In fact stroke was reduced by a $36 \%$ relative risk reduction, and heart failure by $43 \% .{ }^{23}$ However, and this is very interesting, they showed that even if you lower the blood pressure, you did not get a reduction in coronary heart disease, or in all-cause mortality. This is conflicting, because others have shown data where they did actually get a reduction. So, I guess it depends on the study sample size and which studies were chosen to be pooled together in the meta-analysis. But here we see for the first time, that even though systolic blood pressure was reduced, it had no significant effect on coronary heart disease and all-cause mortality.

The question is why are we not seeing a lowering of coronary heart disease? I think the answer lies in the pharmacokinetics and pharmacodynamics, including the vascular effects of the drugs that are prescribed. We need to bear in mind that we need to choose agents that have true 24-hour duration, we need to consider and think about their mode of action, and obviously we need to choose agents that complement each other and not work in the same way. Also it is important to choose agents that lower central blood pressure.

As a cardiologist, obviously I know my patients have coronary plaques and I need to choose agents that will reduce the plaque volume or even regress those atherosclerotic plaques. That is why I choose certain agents over others.

\section{Ambulatory blood pressure, central blood pressure}

Let's look at the first risk factor. It is well-known that ambulatory blood pressure is a much better prediction of cardiovascular risk than office blood pressure. The blood pressure that you take in the office on the patient's arm, serves as a window in time. It gives you an idea. What you need to do is 24-hour ambulatory monitoring which will not only give you a better idea of blood pressure control throughout the day, but 24-hour blood pressure is also a much better predictor of cardiovascular mortality. Different studies have illustrated how steep the ambulatory curve is compared to the office blood pressure curve. ${ }^{24-27}$

Ideally, you're going to choose agents that have true 24hour cover, and these include perindopril (ACE-inhibitor) and amlodipine (calcium channel blocker) which are also recommended by the current hypertension guidelines. What is interesting, is that hydrochlorothiazide, frequently used especially in the State Sector, only lowers blood pressure for a third of the day. For two thirds of the day, there is no effect, because of the short drug half-life. So the question is, is this really an effective blood pressure lowering agent? At the time when we see the patient in the office, the blood pressure looks okay. But at $16 \mathrm{~h} 00$ everybody goes home and guess what happens after that? There is no blood pressure control for the rest of the day. Compare this to indapamide, where we have true 24-hour cover. $^{28,29}$

We need to choose agents that will lower central blood pressure. I know that most of us do not measure central aortic blood pressure, but it is a much better predictor of cardiovascular mortality than brachial blood pressure. ${ }^{30}$ The CAFE study, which was a sub-study of the ASCOT trial, recruited more than 2000 patients and compared atenolol and bendrofluazide to perindopril and amlodipine. At the beginning, blood pressure was elevated and then came down, but there was no significant difference in brachial blood pressure between the two groups. However, perindopril and amlodipine gave a much better and significant reduction of the central aortic blood pressure. This is important, because this reduced central aortic blood pressure translates to improved outcomes. ${ }^{31}$

\section{Antihypertensive treatments and guidelines}

Pragmatically, we use a treatment triangle: If you are seeing the patient for the first time, you should start them on an angiotensin converting enzyme (ACE)-inhibitor or an angiotensin receptor blocker (ARB). Please note you should not combine the two because of the risk of irreversible renal failure. Or, you can start with a calcium channel blocker, or a thiazide, or a thiazide-like diuretic agent. Please note, that atenolol, a beta blocker which is also frequently prescribed in our State Sector, is not in this triangle. Earlier Prof. Nqoba mentioned that ß-blockers play an important role in heart failure and ischaemic heart disease, and therefore remain important agents. I agree, but the problem is that in the State Sector, the ß-blocker that is most frequently prescribed is atenolol. I will show you data that atenolol may be a dangerous drug, especially for patients with coronary artery disease. Also note that Aldomet, Lasix and reserpine should not be in that triangle. Because of their side-effects they are not recommended first-line agents, and although they were used in the olden days, we certainly don't promote their use now.

\section{ACE-inhibitors, ARBs and the benefits of bradykinin}

Let's start at the top of that triangle where we compare the ACE-Is vs the ARBs, because the guidelines say you can choose one or the other. Which one is better? 
Physiologically, if you inhibit the ACE-enzyme with ACE-inhibitor drugs, you ultimately reduce the production of angiotensin II. Well, this is what it is all about. It's about lowering angiotensin II levels. However, ARBs block the angiotensin II receptor, so even though the angiotensin II levels are raised, angiotensin II cannot bind to the receptor. Please note that the production of angiotensin II is not switched off, it is still going on and we know now that angiotensin II, being a potent vasoconstrictor, also promotes fibrosis. For the heart that is bad news, because fibrosis promotes arrhythmias, arrhythmias promote atrial fibrillation $(\mathrm{AF}), \mathrm{AF}$ promotes stroke. High levels of angiotensin II is bad news. ${ }^{31,32}$ Furthermore, and this is important, ACE-Is also raise bradykinin levels. Bradykinin is important, because once you raise the levels of bradykinin, you also increase the levels of nitric oxide. Back to the blood vessel that I showed you, if you raise the nitric oxide levels, you cause vasodilatation, you keep the endothelium healthy and you improve blood flow through the blood vessel, which improves perfusion to the organ, whether that organ is the heart, the brain, the kidneys or the penis. It is important that you open up those blood vessels for the organ to function optimally. ${ }^{32,33}$

Conversely, ARBs have no effect on bradykinin or on nitric oxide levels, and maybe this is why we saw this very interesting phenomenon - that in seven of these ARB trials, in most of them, there was a significant improvement in renal outcomes. They lowered blood pressure. However, there was no reduction at all in any of the cardiovascular or total mortality indices. In the ADVANCE study, however, that recruited more than 11000 diabetic patients, randomising them to the ACE-inhibitor, perindopril, and the thiazide-like diuretic, indapamide, vs placebo, we saw a significant reduction in blood pressure. That's expected; we saw an improvement in renal outcomes, just like the ARBs, but here for the first time we also saw a reduction in cardiovascular mortality of almost $20 \%$ and overall mortality. ${ }^{34}$

In the ACCORD trial, where diabetic patients were randomised to either intensive or standard treatment of blood pressure and glucose, there was a very impressive $14 \mathrm{mmHg}$ reduction in the blood pressure and again, we saw that renal outcomes were improved. ${ }^{35}$ But cardiovascular outcomes were not improved, and the total mortality was also not improved. Why? Because although ACE-inhibitors were one of the drugs in the long list of the antihypertensive agents that they used, perindopril (and indapamide) were not included. So, this is probably not a class effect, but we're seeing specifically that perindopril, which is lipophilic, binds to and penetrates the atherosclerotic plaque and therefore stabilises the plaque. And this is what makes this molecule unique. So I think there's a big change there and if I look at the data, perindopril is certainly the agent that $\mathrm{I}$, as a cardiologist, would prescribe for my patient. ${ }^{35}$

\section{Hydrochlorothiazide vs indapamide}

Ridaq $^{\circledast}$ (hydrochlorothiazide) is used by millions of patients in South Africa. It is cheap and affordable, but it doesn't give you 24-hour blood pressure lowering. In fact, for only a third of the day you may get lowering of the blood pressure compared to indapamide where you get true 24-hour blood pressure reduction. This translates into stroke reduction, total mortality reduction, and very importantly, indapamide is a metabolically neutral agent. It does not interfere with triglycerides or glucose levels, whereas hydrochlorothiazide increases triglyceride levels. And we know that's bad news, because if triglycerides go up, they settle in the pancreas and cause inflammation. In that way they can actually precipitate diabetes mellitus.

Recently there were some studies that reported an association with skin cancer, melanoma and squamous carcinoma, in white users of hydrochlorothiazide. This may not be relevant for our darker Africa, but it certainly is important to remember that it may increase the risk, compared to indapamide that didn't show any such effect at all.

\section{Amlodipine (calcium channel blocker) vs atenolol (beta blocker)}

The ASCOT-BPLA study is well-known. Almost 20000 patients were randomised to atenolol plus/minus a thiazide, or amlodipine plus/minus perindopril. Initially, patients had uncontrolled hypertension and importantly they had other risk factors for atherosclerosis as well. They were followed for five years when the study was actually stopped by the safety monitoring board because they saw some signals that predicted danger. ${ }^{36}$ The mean difference in BP was in favour of treatment with amlodipine and perindopril. However, atenolol plus a thiazide appeared to increase cardiovascular and all-cause mortality. In fact, more patients developed diabetes mellitus on atenolol plus a thiazide. For amlodipine and perindopril, there was a $24 \%$ reduction of cardiovascular mortality and a reduction in all-cause mortality, in a study that was prematurely stopped! These effects might not be entirely explained by better control of blood pressure, because it was only a $2 \mathrm{mmHg}$ reduction. There must be other effects that one should bear in mind when you prescribe your agents. ${ }^{36}$

Prof. Rayner referred to the new 2020 ISH Guidelines and these obviously would have an effect on the South African Guidelines. I am just going to stand still at the final point where it says that we should use agents with evidence of benefits in populations that have been tested.?

\section{In summary}

Back to the cardiovascular continuum: amlodipine and perindopril, perindopril and indapamide have been assessed in big studies with thousands of patients, and have been shown to successfully prevent this wheel from spiralling away. These patients had other cardiovascular risk factors as well. I reiterate: when you start treating the patient, you must hit hard at the beginning, because that is the time that you can reverse it and prevent the build-up of atherosclerosis inside the vessel, which other agents don't do. ${ }^{22}$

When you prescribe an antihypertensive drug, rather prescribe those that give you true 24-hour cover. If it doesn't, consider why you are still prescribing it. Does this drug give the least negative metabolic effects? Does it increase the risk of my 
patients developing diabetes, or an adverse lipid profile? If it does, then I shouldn't prescribe it. Does it have positive pleiotropic effects? Does it raise bradykinin or nitric oxide levels? I want that to be raised because it will improve cardiovascular outcomes. I am not going to prescribe agents that have no effect on nitric oxide or bradykinin levels, and of course I am going to use agents that have outcomes data. I'm going to avoid agents that big trials have shown may be dangerous for my patient.

Finally, George Orwell published 'Animal Farm' in 1945 at the end of World War II, and he said that: "All animals are equal, but some are more equal than others". The book is not just about the Russian Revolution, but it is about the "idea that a free society, is doomed to collapse if the masses remain ignorant of the very ideals they're clinging to". Why then, do we do trials if we don't apply the data to benefit our patients?

\section{Brief rebuttal: Prof. Brian Rayner}

It is very clear, that the dominant effect on cardiovascular and renal outcomes is lowering blood pressure. I don't have a qualm with the majority of what Dr Heradien has said on the nuances of antihypertensive therapies, but you must remember that we've got to look, given the numbers, at the overall costs and the numbers we can treat. Lowering blood pressure even with old agents like captopril and atenolol, reduced outcomes for example in the UKPDS trial. ${ }^{37}$ The ACCORD trial design was marred, leading to a strong interaction between the intensive glucose arm and the intensive blood pressure arm, which negated the benefits. ${ }^{35}$

Regarding hydrochlorothiazide, somebody said hydrochlorothiazide at $12.5 \mathrm{mg}$ should be used as monotherapy. That is almost like a placebo. The dose of hydrochlorothiazide in monotherapy is $25-50 \mathrm{mg}$. That is the evidence-based dose, and I agree that it has more metabolic effects, but nobody has shown that these metabolic effects have translated into worse outcomes. In addition, when hydrochlorothiazide is in combination therapy with other agents, then numerous studies have shown that 24hour blood pressure is maintained. Using indapamide comes with a cost as hydrochlorothiazide is cheaper and you can reach more patients with hypertension. So, I really must say, that getting patients to goal is critically important. If you have the resources, sure, you can go with the nuances, but it comes at a cost.

\section{Brief rebuttal: Dr Marshall Heradien}

It is really about what you prescribe, because if patients experience side-effects, how do you know they are going to be adherent to the therapy? Therefore, my rebuttal is that I would choose agents and discuss upfront with patients what they can expect from this drug which includes side-effects. Although the evidence of cough with an ACE-I is only 3\%, GPs stay away from prescribing ACE-Is because "all the patients come back with coughing". That's not true. You will probably find the incidence is higher with smokers, than non-smokers. They need to stop smoking anyway. Regarding the ACE-I effect, perindopril is better than enalapril because you have to take enalapril twice daily - it is not a once daily dosage. The moment you start adding and asking people to take their drugs twice daily, there is a risk that they will probably only take it once daily, or maybe not at all over weekends like when they're drinking.

I would also choose agents that give additional benefits, specifically regarding plaque stability, not just lowering blood pressure. And yes, I know that statins play an important role there, but we know that they may give muscle cramps and other side-effects. Your point about cost is very valid, especially now that we are not going to have any money left after COVID-19, and that's where I think the pharmaceutical companies should lower the prices of drugs that are better. Studies have shown better outcomes than with the old drugs. I know it is about cost, but if we are making more diabetics, we are getting worse outcomes.

\section{References}

1. Kotchen TA. Historical trends and milestones in hypertension research: a model of the process of translational research. Hypertension. 2011;58(4):522-38. https:// doi.org/10.1161/HYPERTENSIONAHA.111.177766.

2. Lewington S. Prospective Studies Collaboration. Age-specific relevance of usual blood pressure to vascular mortality: a meta-analysis of individual data for one million adults in 61 prospective studies. Lancet. 2002;360:1903-13. https://doi org/10.1016/S0140-6736(02)11911-8.

3. Effects of treatment on morbidity in hypertension. Results in patients with diastolic blood pressures averaging 115 through $129 \mathrm{mmHg}$. JAMA. 1967;202:1028-34. Available from: https://pubmed.ncbi.nlm.nih.gov/4862069/.

4. Chobanian AV, Bakris GL, Black HR, et al.; National Heart, Lung, and Blood Institute Joint National Committee on Prevention, Detection, Evaluation, and Treatment of High Blood Pressure; National High Blood Pressure Education Program Coordinating Committee. The Seventh Report of the Joint National Committee on Prevention, Detection, Evaluation, and Treatment of High Blood Pressure: the JNC 7 report. JAMA. 2003;289(19):2560-72. https://doi.org/10.1001/ jama.289.19.2560.

5. Bundy JD, Li C, Stuchlik P, et al. Systolic blood pressure reduction and risk of cardiovascular disease and mortality: a systematic review and network meta-analysis. JAMA Cardiol. 2017;2:775-81. https://doi.org/10.1001/ jamacardio.2017.1421.

6. Egan BM, Kjeldsen SE, Grassi G, Esler M, Mancia G. The global burden of hypertension exceeds 1.4 billion people: should a systolic blood pressure target below 130 become the universal standard? J Hypertens. 2019;37(6):1148-53. https://doi.org/10.1097/HJH.0000000000002021.

7. Unger T, Borghi C, Charchar F, et al. 2020 International Society of Hypertension global hypertension practice guidelines. Hypertension. 2020;75(6):1334-57. https://doi.org/10.1161/HYPERTENSIONAHA.120.15026

8. Mills KT, Bundy JD, Kelly TN, et al. Global disparities of hypertension prevalence and control: a systematic analysis of population-based studies from 90 countries. Circulation. 2016;134(6):441-50. https://doi.org/10.1161/ CIRCULATIONAHA.115.018912

9. Bradshaw D, Groenewald P, Laubscher R. Initial estimates from the South African National Burden of Disease Study, 2000. MRC Policy Brief. No 1. March 2003. 2011. Available from: https://www.samrc.ac.za/sites/default/files/ attachments/2016-06-30/initialbodestimates.pdf.

10. Norman R, Bradshaw D, Schneider M, et al. A comparative risk assessment for South Africa in 2000: towards promoting health and preventing disease. S Afr Med J. 2007;97(8):637-41.

11. Campbell NR, Lackland DT, Niebylski ML, League WH, Committees ISoHE. High blood pressure: why prevention and control are urgent and important-a 2014 fact sheet from the World Hypertension League and the International Society of Hypertension. The Journal of Clinical Hypertension. 2014;16(8):551-3. https://doi. org/10.1111/jch.12372.

12. Thomas $G$, Xie $D, C$ hen $H-Y$, et al. Prevalence and prognostic significance of apparent treatment resistant hypertension in chronic kidney disease: report from the Chronic Renal Insufficiency Cohort Study. Hypertension. 2016;67(2):387-96. https://doi.org/10.1161/HYPERTENSIONAHA.115.06487. 
13. Fatemi O, Goa C, Faselis C, Kokkinos P, Papademetriou V. Improvement in all-cause mortality with blood pressure control in a group of US veterans with drug-resistant hypertension. The Journal of Clinical Hypertension. 2016;18(1):339. https://doi.org/10.1111/jch.12672.

14. Chow CK, Teo KK, Rangarajan S, et al. Prevalence, awareness, treatment, and control of hypertension in rural and urban communities in high-, middle-, and low-income countries. JAMA. 2013;310(9):959-68. https://doi.org/10.1001/ jama.2013.184182.

15. Ataklte F, Erqou S, Kaptoge $S$, et al. Burden of undiagnosed hypertension in sub-Saharan Africa. A Systematic Review and Meta-Analysis. Hypertension. 2015;65(2):291-8. https://doi.org/10.1161/HYPERTENSIONAHA.114.04394.

16. Berlowitz DR, Ash AS, Hickey EC, et al. Inadequate management of blood pressure in a hypertensive population. N Engl J Med. 1998;339(27):1957-63. https://doi.org/10.1056/NEJM199812313392701

17. Falaschetti E, Mindell J, Knott C, Poulter N. Hypertension management in England: a serial cross-sectional study from 1994 to 2011. Lancet. 2014;383(9932):1912-9. https://doi.org/10.1016/S0140-6736(14)60688-7.

18. De Beus E, Bots ML, Van Zuilen AD, Wetzels JF, Blankestijn PJ. Prevalence of apparent therapy-resistant hypertension and its effect on outcome in patients with chronic kidney disease. Hypertension. 2015;66(5):998-1005. https://doi. org/10.1161/HYPERTENSIONAHA.115.05694.

19. Go AS, Bauman MA, Coleman King SM, et al. An effective approach to high blood pressure control: a science advisory from the American Heart Association, the American College of Cardiology, and the Centers for Disease Control and Prevention. Hypertension. 2014;63(4):878-85. https://doi.org/10.1161/ HYP.0000000000000003.

20. Hoy WE, Kondalsamy-Chennakesavan SN, Nicol JL. Clinical outcomes associated with changes in a chronic disease treatment program in an Australian Aboriginal community. Med J Aust. 2005;183(6):305-9. https://doi. org/10.5694/j.1326-5377.2005.tb07060.x.

21. Bailie RS. Clinical outcomes associated with changes in a chronic disease treatment program in an Australian Aboriginal community. Med J Aust. 2006 Aug 7;185(3):180-1. https://doi.org/10.5694/j.1326-5377.2006.tb00517.x.

22. Dzau VJ, Antman EM, Black HR, et al. The cardiovascular disease continuum validated: clinical evidence of improved patient outcomes: part I: Pathophysiology and clinical trial evidence (risk factors through stable coronary artery disease). Circulation. 2006;114(25):2850-70. https://doi.org/10.1161/ CIRCULATIONAHA.106.655688.

23. Thomopoulos C, Parati G, Zanchetti A. Effects of blood pressure lowering on outcome incidence in hypertension: 4. Effects of various classes of antihypertensive drugs-overview and meta-analyses. J Hypertens. 2015;33(2):195-211. https://doi.org/10.1097/HJH.0000000000000447.

24. Mancia G, Verdecchia P. Clinical value of ambulatory blood pressure: evidence and limits. Circ Res. 2015;116(6):1034-45. https://doi.org/10.1161/ CIRCRESAHA.116.303755

25. Staessen JA, Thijs $L$, Fagard $R$, et al. Predicting cardiovascular risk using conventional vs ambulatory blood pressure in older patients with systolic hypertension. JAMA. 1999;282(6):539-46. https://doi.org/10.1001/ jama.282.6.539.

26. Dolan E, Stanton A, Thijs L, et al. Superiority of ambulatory over clinic blood pressure measurement in predicting mortality: the Dublin outcome study. Hypertension. 2005;46(1):156-61. https://doi.org/10.1161/01. HYP.0000170138.56903.7a.

27. Sega $R$, Facchetti $R$, Bombelli $M$, et al. Prognostic value of ambulatory and home blood pressures compared with office blood pressure in the general population: follow-up results from the Pressioni Arteriose Monitorate e Loro Associazioni (PAMELA) study. Circulation. 2005;111(14):1777-83. https://doi.org/10.1161/01. CIR.0000160923.04524.5B.

28. Flack JM, Nasser SA. Benefits of once-daily therapies in the treatment of hypertension. Vascular Health and Risk Management. 2011;7:777. https://doi. org/10.2147/VHRM.S17207.

29. Lacourciere Y, Poirier L, Lefebvre J, et al. Antihypertensive effects of amlodipine and hydrochlorothiazide in elderly patients with ambulatory hypertension. Am J Hypertens. 1995;8(12):1154-9. https://doi.org/10.1016/0895-7061(95)00362-2.

30. Wang K-L, Cheng H-M, Chuang S-Y, et al. Central or peripheral systolic or pulse pressure: which best relates to targetorgans and future mortality? J Hypertens. 2009;27(3):461. https://doi.org/10.1097/HJH.0b013e3283220ea4.

31. Agabiti-Rosei E, Mancia G, O'Rourke MF, et al. Central blood pressure measurements and antihypertensive therapy: a consensus document. Hypertension. 2007;50(1):154-60. https://doi.org/10.1161/ HYPERTENSIONAHA.107.090068.

32. Messerli FH, Weber MA, Brunner HR. Angiotensin II receptor inhibition: a new therapeutic principle. Arch Intern Med. 1996;156(17):1957-65. https://doi. org/10.1001/archinte.1996.00440160069010.

33. Epstein BJ, Gums JG. Angiotensin receptor blockers versus ACE inhibitors: prevention of death and myocardial infarction in high-risk populations. Ann Pharmacother. 2005;39(3):470-80. https://doi.org/10.1345/aph.1E478.

34. Garcia-Donaire J, Segura J, Cerezo C, Ruilope L. A review of renal, cardiovascular and mortality endpoints in antihypertensive trials in diabetic patients. Blood Press. 2011;20(6):322-34. https://doi.org/10.3109/08037051.2011.602878.

35. Buse JB; The ACCORD Study Group. Action to Control Cardiovascular Risk in Diabetes (ACCORD) trial: design and methods. The American Journal of Cardiology. 2007;99(12):S21-S33. https://doi.org/10.1016/j.amjcard.2007.03.003.

36. Dahlof B, Sever PS, Poulter NR, et al. Prevention of cardiovascular events with an antihypertensive regimen of amlodipine adding perindopril as required versus atenolol adding bendroflumethiazide as required, in the Anglo-Scandinavian Cardiac Outcomes Trial-Blood Pressure Lowering Arm (ASCOT-BPLA): a multicentre randomised controlled trial. The Lancet. 2005;366(9489):895-906. https://doi.org/10.1016/S0140-6736(05)67185-1.

37. King P, Peacock I, Donnelly R. The UK prospective diabetes study (UKPDS): clinical and therapeutic implications for type 2 diabetes. Br J Clin Pharmacol. 1999;48(5):643-8. https://doi.org/10.1046/j.1365-2125.1999.00092.x. 